\title{
The effects of a single injection of dexamethasone-21-isonicotinate on the lymphocyte functions of dairy cows at two weeks post partum
}

\author{
Jitkamol THANASAK ${ }^{\mathrm{a}, \mathrm{b} *}$, Ruurd JORRITSMA ${ }^{\mathrm{a}}$, Aad HOEK $^{\mathrm{c}}$, \\ Jos P.T.M. NOORDHUIZEN ${ }^{\mathrm{a}}$, Victor P.M.G. RUTTEN ${ }^{\mathrm{c}}$, \\ Kerstin E. MÜLLER ${ }^{a}$ \\ a Department of Farm Animal Health, Faculty of Veterinary Medicine, Yalelaan 7, Utrecht, \\ The Netherlands \\ ${ }^{b}$ Faculty of Veterinary Science, Mahidol University, Salaya, Phuttamonthon, \\ Nakhon-Pathom, 73170, Thailand \\ ${ }^{c}$ Department of Infectious Deseases and Immunology, Division of Immunology, \\ Faculty of Veterinary Medicine, Yalelaan 1, Utrecht, The Netherlands
}

(Received 6 June 2003; accepted 12 August 2003)

\begin{abstract}
Dexamethasone is a potent therapeutic for treatment of the fatty liver syndrome or primary ketosis in post partum dairy cows. Reservations exist, however, among practitioners with respect to the risk of immunosuppression induced by corticosteroids. The aim of this study was to investigate the effect of a single injection of dexamethasone-21-isonicotinate on distinct immune functions of postpartum dairy cows because only scarce information is available on the effects of corticosteroid preparations when administered at a dosage and frequency for treatment of the fatty liver syndrome or primary ketosis. Sixteen Swedish red-pied dairy cows, between days 9 and 15 post partum, were allotted to either a control group $(n=8)$ or a treatment group $(n=8)$. The cows in the treatment group received a single intramuscular injection of a dexamethasone-21-isonicotinate suspension at a dosage of $0.02 \mathrm{mg} / \mathrm{kg}$ i.m. at the start of the experiment. White blood cell counts and selected lymphocyte functions (lymphocyte proliferation, expression of lymphocyte markers and the $\beta 2$ and $\alpha 4$ chain of adhesion molecules belonging to the integrin family) and some parameters of the energy metabolism (glucose, insulin) were determined before the administration of corticosteroids (day 0) and subsequently at days 2, 4, 7 and 9 of the experiment. Changes in glucose and insulin were within the target range for treatment of the fatty liver syndrome or primary ketosis. Significant $(P<0.05)$ increases in the number of circulating white blood cells were observed in treated cows on the second day following treatment which was exclusively caused by an increase in the number of circulating neutrophils. Lymphocyte blastogenesis in response to ConA and the percentages of lymphocytes positive for CD2, CD4, CD8, CD49d and CD18 as well as the intensity of CD49d expression did not differ between the treatment and control groups. There was, however, a significant reduction $(P<$ $0.01)$ in the intensity of CD18 expression on lymphocytes in the treated animals on the fourth day after treatment. In conclusion, a single administration of dexamethasone-21-isonicotinate in a dosage of $0.02 \mathrm{mg} / \mathrm{kg}$ i.m. at two weeks post partum in healthy cows had a significant but highly transient effect on CD18 expression on lymphocytes and the number of peripheral blood neutrophils, but did not affect lymphocyte blastogenesis or lymphocyte subpopulation patterns in peripheral blood.
\end{abstract}

glucocorticosteroid / ketosis / lymphocyte proliferation / adhesion molecules / dairy cows

* Corresponding author: j.thanasak@ vet.uu.nl 


\section{INTRODUCTION}

In ruminants, the placenta and the udder have an obligatory requirement for glucose. Due to increased energy requirements caused by milk production, high yielding postpartum dairy cows are at risk of developing hypoglycemia and ketosis. Hypoglycemia induces lipolysis in adipose tissues resulting in increased levels of non-esterified fatty acids (NEFA) in the blood. These NEFA are transported to the liver and, due to insufficient export from the liver by lipoproteins, fat is deposited as triacylglycerol (TAG) in this organ. Cows being overconditioned at the end of pregnancy are at risk of accumulation of moderate $(>10 \%)$ or even high $(>20 \%)$ amounts of TAG in the liver; such cows have been shown to be more susceptible to disease $[35,40]$.

Glucocorticosteroid preparations have been shown to be beneficial in the treatment of ketosis and fatty liver syndrome of postpartum dairy cows [3, 31, 37, 41]. They enhance the mobilization of glucose precursors (amino acids) and stimulate the rate of gluconeogenesis [19]. In practice, the use of glucocorticosteroids in postpartum cows, however, is limited since a great number of veterinarians share the common perception that these drugs are contraindicated due to their potential to induce immunosuppression. Reports on the immunomodulating capacities of glucocorticosteroids, however, include a wide variety of preparations, dosages, numbers of treatments and routes of administration [2, 8, 14, 16, 27]. Glucocorticosteroids have been shown to cause leukocytosis involving neutrophilia and lymphopenia [36], suppression of leukocyte blastogenesis [26, 30, 33] and to change T-lymphocyte subpopulation patterns $[2,8,16]$. The increase in the number of circulating neutrophils following the administration of glucocorticosteroids has been well explained by the down-regulation of L-selectin and adhesion molecules of the $\beta 2$-integrin family on these cells, resulting in an impaired ability of neutrophils to leave the circulation $[9,23]$. In addition, an increased release of neutrophils from bone marrow has been observed following the administration of corticosteroids [32]. Oldham and Howard [27] have shown that daily intramuscular injections of dexamethasone at a dosage of $0.5 \mathrm{mg} / \mathrm{kg} /$ day in calves for 20 days results in neutrophilia and lymphopenia with a significant reduction in the number of $\mathrm{CD} 2^{+} \mathrm{T}$ cells without apparent differences in $\mathrm{CD} 4^{+}$ and $\mathrm{CD}^{+}$subpopulations. Moreover, a single intramuscular injection of $0.2 \mathrm{mg} / \mathrm{kg}$ dexamethasone induced lymphopenia associated with decreased numbers of circulating $\mathrm{CD}^{+}$and $\mathrm{CD}^{+}{ }^{+} \mathrm{T}$ cells without changes in the number of circulating $\mathrm{CD}^{+}$ $\mathrm{T}$ cell populations in cows [16]. These changes in the number of circulating lymphocytes and lymphocyte subsets are thought to be the effects of glucocorticosteroid on the expression of lymphocyte adhesion molecules that mediate cell-cell interactions and leukocyte extravasation. Such a decrease in expression could impair lymphocyte adhesion to lymphatic vessels in the tissues with a consequent decreased re-entry into the circulation [5, 21, 29]. In addition, glucocorticosteroid can affect lymphocyte redistribution, particularly to the bone marrow [13, 43].

Although abundant information is available on the immunosuppressive effects of various glucocorticosteroid preparations in cattle, there is hardly any information whether this is also true in the case of glucocorticosteroids administered in the dosage recommended for treatment of ketosis. Thus the purpose of the present study was to investigate the effect of a single injection of dexamethasone-21-isonicotinate on parameters related to lymphocyte functions in dairy cows versus untreated controls. Lymphocyte proliferation, expression of lymphocyte adhesion molecules and lymphocyte subsets were repeatedly determined in postpartum dairy cows for a 9-day period following treatment, and the results were compared to those of untreated controls. 


\section{MATERIALS AND METHODS}

\subsection{Experimental animals}

Sixteen healthy lactating dairy cows of the Swedish red-pied breed, aged between 2 and 2.5 years were included in this study. The animals were kept in tied stalls on straw bedding. The study was conducted under the supervision and with the approval of the Ethical Review Committee of Animal Experimentation of the Faculty of Veterinary Medicine, Utrecht University, The Netherlands.

\subsection{Dexamethasone administration}

Between days 9 and 15 post partum the animals were assigned either to the treatment group $(n=8)$ (DEX) or to the control group ( $n=8)$ (control). The treatment consisted of a single i.m. injection of a suspension of dexamethasone-21-isonicotinate (Voreen ${ }^{\circledR}$ Suspension, Boehringer Ingelheim, Germany) in a dosage of $1 \mathrm{mg}$ dexamethasone-21-isonicotinate (DEX) per $50 \mathrm{~kg}$ bodyweight $(0.02 \mathrm{mg} / \mathrm{kg})$ administered between days 9 and 15 after calving. The animals in the control group received no treatment.

\subsection{Blood sampling, haematology and blood biochemistry}

Blood samples were taken from the jugular vein into appropriate tubes (Vacuette ${ }^{\circledR}$ Greiner Labortechnik, Germany) before the administration of corticosteroids (day 0) and subsequently at days 2, 4, 7 and 9 following the injection of dexamethasone-21isonicotinate. The following parameters were determined: the number of red blood cells (RBC) and the number of white blood cells (WBC) using an electronic cell counter (Sysmex K-1000, Toa Medical Instruments, Kobe, Japan). Differentials were determined after staining with May/Grünwald-Giemsa (Merk Diagnostika, Darmstadt, Germany). The levels of plasma glucose were determined using a commercial test kit (kit 442640, Beckman Instruments B.V., Mijdrecht, The Netherlands). Serum insulin concentrations were determined using a radio immuno assay kit (Coat-a-Count ${ }^{\circledR}$ Insulin, Diagnostic Products Corporation, Los Angeles, USA).

\subsection{Preparation of peripheral blood mononuclear cells}

Peripheral blood mononuclear cells (PBMC) were isolated by dilution (1:1) of heparinized peripheral blood in RPMI1640 (Gibco Grand Island, NY, USA) supplemented with heparin $(5 \mathrm{IU} / \mathrm{mL})$ (Liquemin, Hoffmann LaRoche, Basel, Switzerland), penicillin (100 IU/mL) and streptomycin $(100 \mu \mathrm{g} / \mathrm{mL})$ and subsequent density gradient centrifugation on Ficoll Isopaque $(d=1.078 \mathrm{~g} / \mathrm{mL}$; Pharmacia, Freiburg, Germany). PBMC were collected from the interphase, then washed in RPMI1640 twice, and the final pellet was resuspended in culture medium. The culture medium consisted of RPMI-1640 supplemented with penicillin $(50 \mathrm{IU} / \mathrm{mL})$, streptomycin $(50 \mu \mathrm{g} / \mathrm{mL})$, L-glutamine $(2 \mathrm{mM})$, 32-mercapto-ethanol $\left(2 \times 10^{-5} \mathrm{M}\right)$ and $10 \%$ fetal bovine serum (FBS).

\subsection{Lymphocyte proliferation assays}

Proliferation assays were performed by culturing $2 \times 10^{5} \mathrm{PBMC}$ in $200 \mu \mathrm{L}$ culture medium with $(10 \mu \mathrm{g} / \mathrm{mL})$ and without ConA in 96-well flat-bottom tissue culture plates for 4 days at $37{ }^{\circ} \mathrm{C}$ in a humidified atmosphere of $5 \% \mathrm{CO}_{2}$ in air. During the last 18 hours of culture, cells were pulsed with $0.4 \mu \mathrm{Ci}\left[{ }^{3} \mathrm{H}\right]$-thymidine $(1.0 \mathrm{Ci} / \mathrm{mmol}$; Amersham, Bucks, UK) added in $30 \mu \mathrm{L}$ per well. The incorporation of labeled DNA was assessed by liquid scintillation counting in a Betaplate-counter (Pharmacia Freiburg, Germany). The results obtained were expressed as mean counts per minute (cpm), and stimulation index (SI: The ratio of antigen-specific proliferation and 

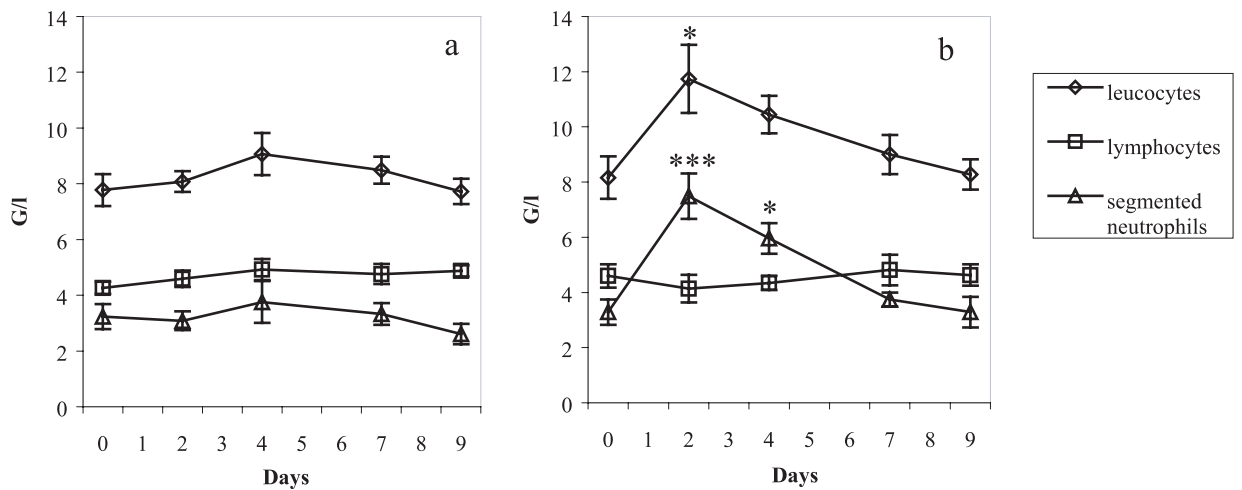

Figure 1. Total leucocyte numbers, numbers of lymphocytes and segmented neutrophils (giga per liter, $\mathrm{G} / \mathrm{L})$ in control cows $(n=8)$ (a) and cows treated with dexamethasone-21-isonicotinate (DEX group; $n=8$ ) (b). The values are expressed as mean and SEM. $* P<0.05$, $* * * P<0.001$ when compared with control values. The samples were obtained at the start of the experiment (day 0 ), before animals of the DEX-group were treated and subsequently at days 2, 4, 7 and 9 .

background proliferation) with the standard error of the mean (SEM).

\subsection{Cell surface phenotyping by flow cytometry}

Briefly, after the preparation of PBMC, the cells were labeled with monoclonal antibodies $(\mathrm{mAb})$ specific for bovine leukocyte markers CD2, CD4, CD8, CD18 and CD49d (VLA-4 $\alpha$-chain) followed by goat anti-mouse Ig RPE (Southern Biotechnology Associates, Inc., Birmingham, USA) as the second step. All mAbs used in this study have been described previously: IL-A42, anti-bovine CD2 [15]; IL-A11, anti-bovine CD4 [4]; IL-A51, anti-bovine CD8 [17]; $\mathrm{R} 15.7$, anti-canine CD18 cross reactive with bovine CD18 [6, 18]; BII 218.1, antisheep CD49d crossreactive with bovine cells [25]. UD15 directed against chloramphenicol [39] served as negative control.

The percentage of cells and geometric mean fluorescence intensity (MFI) resulting from the immunolabeling were determined on 10000 PBMC, using a FacsCalibur (Becton Dickinson, San José, USA). Lymphocytes were gated on the basis of their forward and side scatter characteristics in dot plots. Then the percentages of gated cells staining positive for CD2, CD4, CD8, CD18 and CD49d were calculated as well as the geometric mean fluorescence intensities (MFI) of CD18 and CD49d.

\subsection{Statistics}

The means of normal distributed data were evaluated for statistical significance using the independent-samples t-test, an option of the SPSS computer program [38] for Windows.

\section{RESULTS}

\subsection{Haematology and blood biochemistry}

The mean total white blood cell count of DEX treated animals was significantly increased at day 2 following treatment compared to untreated controls $(P<0.05)$. The increase in the number of segmented neutrophils was significant at days 2 and $4(P<$ 0.001 and $P<0.05$ respectively). Total WBC and neutrophil counts returned to normal by day 4 and 7 following DEX treatment, respectively (Fig. 1). The numbers 

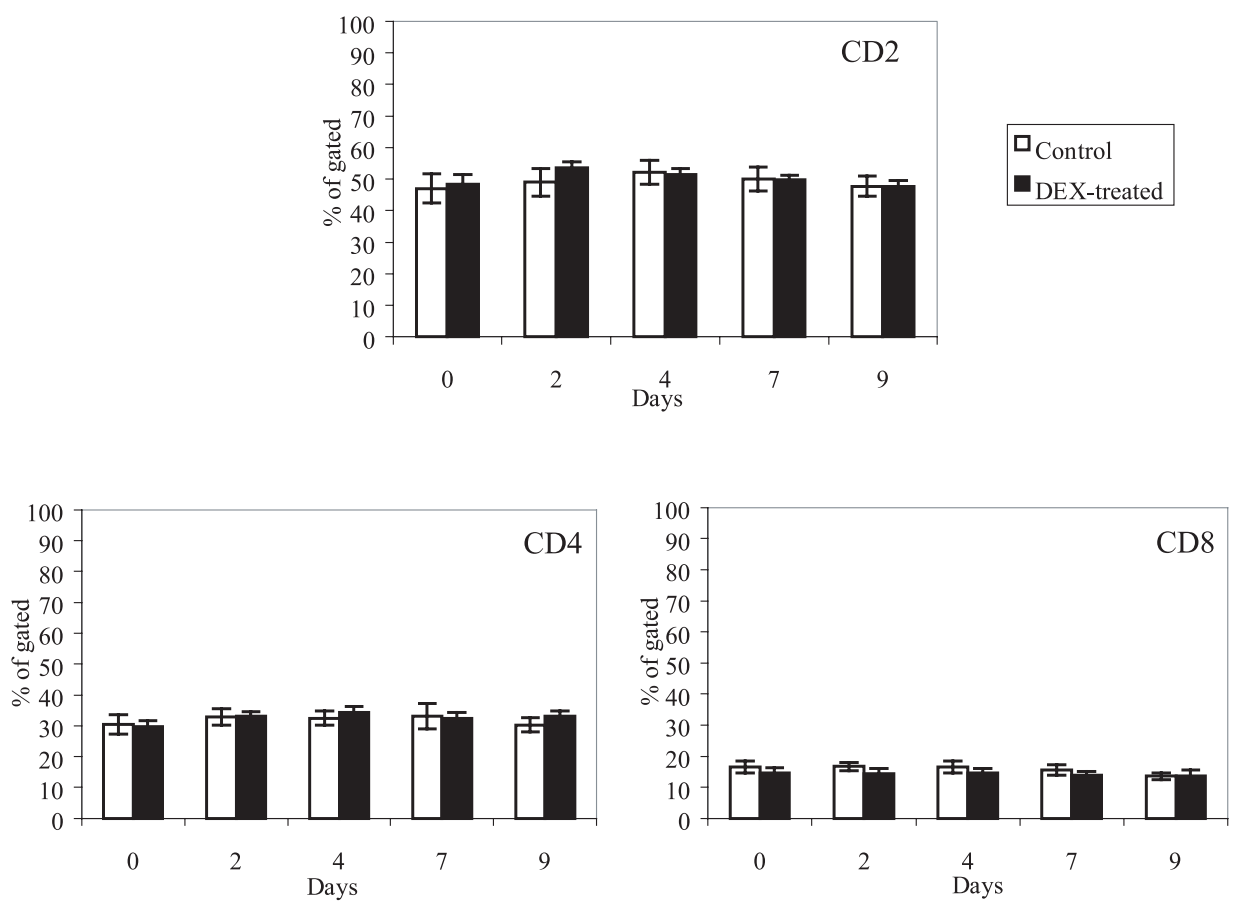

Figure 2. Percentage (mean \pm SEM) of circulating CD2, CD4 and CD8 positive lymphocytes in postpartum dairy cows treated with dexamethasone-21-isonicotinate (DEX-group; $n=8$ ) and untreated controls $(n=8)$. The samples were obtained at the start of the experiment (day 0 ), before the animals of the DEX-group were treated and subsequently at days 2, 4, 7 and 9.

of lymphocytes, monocytes, band neutrophils, eosinophils and basophils did not differ significantly between the DEX group and the controls (data not shown).

Significant increases were observed in the plasma glucose $(P<0.05)$ and insulin $(P<0.05)$ levels at day 2 after treatment in the DEX treated animals versus the controls. Mean plasma glucose concentrations at day 2 of the study were $3.55 \mathrm{mmol} / \mathrm{L}$ $(\mathrm{SEM}=0.16)$ and $3.18 \mathrm{mmol} / \mathrm{L}(\mathrm{SEM}=$ $0.10)$ in the treated animals and controls respectively. Mean plasma insulin concentrations at day 2 of the study were $13.14 \mu \mathrm{IU} / \mathrm{mL}(\mathrm{SEM}=2.29)$ and $3.59 \mu \mathrm{IU} /$ $\mathrm{mL}(\mathrm{SEM}=1.05)$ in the treated animals and controls respectively. (Mean plasma concentrations at day 0 were $3.14 \mathrm{mmol} / \mathrm{L}$ $(\mathrm{SEM}=0.11)$ for glucose and $3.48 \mu \mathrm{IU} / \mathrm{mL}$ $(\mathrm{SEM}=1.15)$ for insulin.)

\subsection{Flow cytometric analysis}

\subsubsection{T-cells}

At no time were significant differences found in the percentage of circulating $\mathrm{CD} 2^{+}, \mathrm{CD}^{+}{ }^{+}$and $\mathrm{CD}^{+}$cells between the animals treated with DEX and the controls (Fig. 2).

\subsubsection{Lymphocyte adhesion molecules}

The percentages of circulating lymphocytes, staining positive for CD18 and CD49d were similar in both groups throughout the experiment. The expression of CD18 as expressed by geometric mean fluorescence intensity (MFI) was significantly lower in the animals treated with DEX as compared to the controls $(P<0.01)$ 

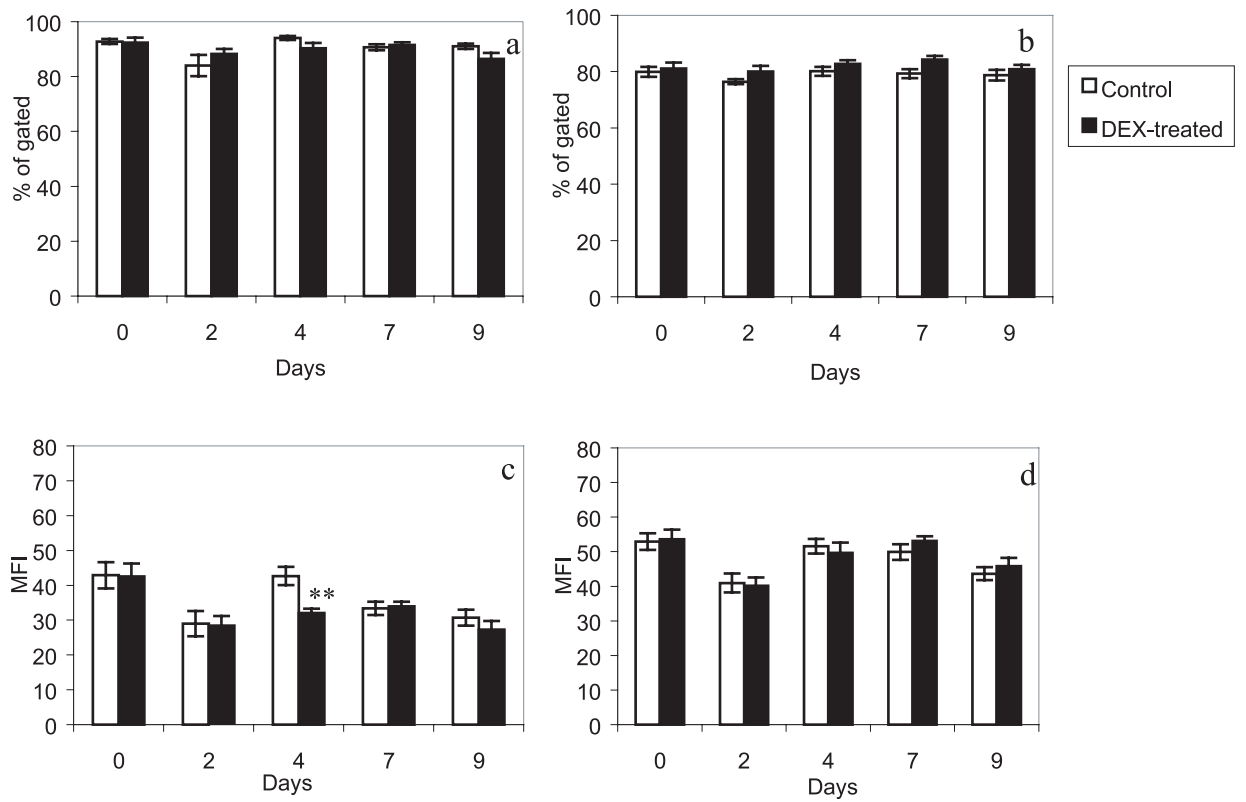

Figure 3. The expression of adhesion molecules on lymphocytes of postpartum cows treated with dexamethasone-21-isonicotinate (DEX-group; $n=8)$ and untreated controls $(n=8)$. The percentage (mean \pm SEM) of cells in the lymphocyte gate positive for CD18 is shown in (a) and for CD49d in (b). Geometric mean fluorescence intensity (MFI) of CD18 is presented in (c) and CD49d expression on peripheral blood lymphocytes is given in (d). The samples were obtained from DEXtreated animals $(n=8)$ and controls $(n=8)$ at the start of the experiment before treatment (day 0$)$ and subsequently at days $2,4,7$ and 9 .** $P<0.01$ when compared with control values.

on day 4 after treatment. The expression of CD49d was not altered (Fig. 3).

\subsection{Proliferative response to ConA}

Lymphocyte proliferation in response to ConA did not show significant differences between the control and DEX treated animals when the counts per minute (cpm) or stimulation indices (SI) were compared (Fig. 4).

\section{DISCUSSION}

In the present study, a single intramuscular injection of $0.02 \mathrm{mg} / \mathrm{kg}$ of dexamethasone-21-isonicotinate in dairy cows at about two weeks post partum caused significant increases in the absolute number of circulating white blood cells at day two after treatment and in the number of circulating neutrophils at days two and four after treatment. No significant differences were found in either the mitogen-induced proliferation of lymphocytes or in the percentages of cells expressing CD2, CD4, CD8 lymphocyte markers and cell adhesion molecules CD18 and CD49d between treated and untreated animals. The intensity of CD18 expressed on lymphocytes, however, was significantly but transiently reduced in DEX treated animals.

The leukocytosis observed in cows treated with DEX on day 2 was mainly caused by neutrophilia. Carlson and Kaneko [11] have shown that the increased number of neutrophils in the circulation after stress or the administration of glucocorticosteroids is caused by several factors: the input of mature neutrophils from the bone 


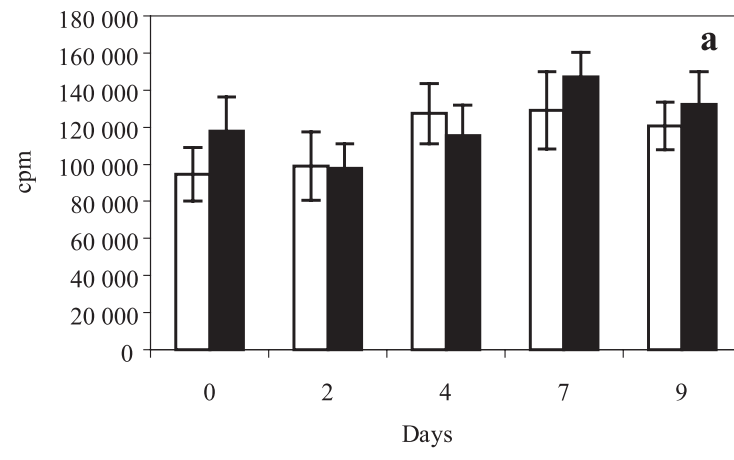

$$
\begin{array}{|l|}
\hline \mathbf{}_{\text {Control }} \\
\mathbf{m}_{\text {DEX-treated }} \\
\hline
\end{array}
$$

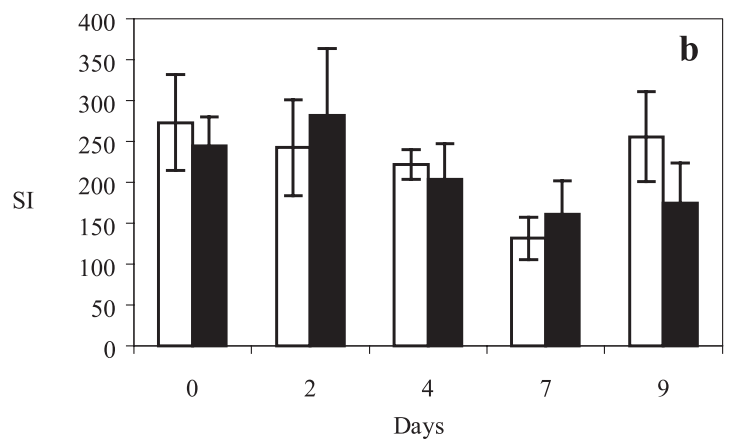

$\square_{\text {Control }}$

DEX-treated

Figure 4. Lymphoproliferative responses (mean $\pm \mathrm{SEM}$ ) to ConA in postpartum dairy cows treated with dexamethasone-21-isonicotinate (DEX-group; $n=8)$ and untreated controls $(n=8)$. The samples were obtained at the start of the experiment (day 0), before the animals of the DEX-group were treated and subsequently at days 2, 4,7 and 9. The results are presented as counts per minute (cpm) (a) and stimulation indices (SI) (b).

marrow storage pool, a decreased extravasation of neutrophils into the tissue and a reduced margination of neutrophils. Decreased margination of neutrophils might be caused by the recognized ability of corticosteroids to reduce neutrophil adhesion to the vascular endothelium. This effect is well explained by the decreased expression of adhesion molecules of the L-selectin and $\beta_{2}$-integrin (CD18) families on neutrophils $[7,9,23]$ in combination with the inhibition of the expression of endothelial-leukocyte adhesion molecule 1 (ELAM-1) and intercellular adhesion molecule 1 (ICAM-1) [12]. Although these changes impair neutrophil migration kinetics, which increase susceptibility to infectious diseases, such as bovine mastitis, they require additional immunological investigations. Since abundant literature is available on glucocorticoid induced changes on granulocytes and the main focus of our study was lymphocyte function related parameters, we did not investigate the expression of CD18 and CD49d on granulocytes.

Considering the population of lymphocytes in our study, DEX treatment did not induce a significant decrease in the number of circulating lymphocytes or changes in lymphocyte subsets (CD2, CD4 and CD8 cells) (Figs. 1 and 2). Our findings are in accordance with the investigations of Burton and Kehrli [8] who demonstrated that the percentages of $\mathrm{CD}^{+}, \mathrm{CD}^{+}$and $\mathrm{CD}^{+} \mathrm{T}$ cells are not altered by $0.04 \mathrm{mg} / \mathrm{kg} /$ day dexamethasone administered to young 
bulls on three consecutive days. However, in other studies glucocorticosteroids have been shown to cause lymphopenia and alterations of lymphocyte subsets [2, 14, $16,42]$. Thus, the differences between the results of previous studies and the present one can mainly be explained by the differences in the sort of corticosteroids administered as well as differences in the age of the probands, the dosage regimen and the number of treatments.

Trafficking patterns of T-lymphocytes have been shown to rely on the expression of adhesion molecules belonging to the selectin and integrin families, which mediate lymphocyte migration and homing [10]. Even though, the present data show that a single administration of dexamethasone21-isonicotinate did not influence the percentages of circulating lymphocytes expressing $\beta_{2}$-integrins (CD18) and $\alpha_{4}$-integrins (CD49d), the density of $\beta_{2}$-integrins (CD18) on lymphocytes was shown to be significantly lower in the treated animals versus the controls on day 4 following the treatment $(P<0.01)$. This phenomenon, however, was not found for the CD49d expression. One of the mechanisms of the anti-inflammatory activity of corticosteroids is the inhibition of the release of arachidonic acid (AA) from cellular phospholipids and as a consequence of prostaglandin (PG) synthesis [22]. The downmodulation of CD18 might be explained both by the changes in membrane fluidity and decreased PG synthesis. Our findings were partially supported by the observations of in vitro studies in which glucocorticosteroids were shown to decrease lymphocyte adhesion to the endothelium as well as intercellular interactions through the inhibition of LFA-1 and CD2 up-regulation and of the steady state mRNA levels of LFA-1 and CD2 genes production [29] resulting in the interference with lymphocyte recirculation patterns which could form one explanation for reduced specific immune responsiveness [1]. The significant though transient effect of DEX on
CD18 expression at day 4 could involve LFA-1 down-modulation. Thus the potential effect of DEX on preformed storage is likely to be of less relevance. It may rather be the impaired transcription of CD18, impaired heterodimerization of CD11a/ CD18 or altered avidity of CD18 for the antibody used as described for neutrophils [7] that explains our finding.

In the present study a single injection with DEX did not affect Con A-induced lymphocyte proliferation. In previous studies, however, single injections with high doses or repeated treatments resulted in decreased lymphocyte proliferation [24, $30,34]$. One possible mechanism underlying the reduced lymphocyte proliferative responses is the down modulation of CD18 expression. The latter molecule has been shown to act as a co-stimulatory molecule in the process of lymphocyte proliferation. Although we found reduced CD18 expression on lymphocytes in DEX treated cows in this study, their proliferative responses remained unaffected. The depression of lymphocyte proliferation was also shown to relate to increased blood glucose concentrations [20]. Although increases in blood glucose and insulin concentration in the DEX treated group indicated that hypoglycemia was overcome, in accordance with earlier observations [28, 36, 41], they did not affect lymphocyte proliferation in the present study.

In conclusion, a single injection of dexamethasone-21-isonicotinate at the dosage recommended by the manufacturer $(0.02 \mathrm{mg} / \mathrm{kg})$ for treatment of ketosis in dairy cows at two weeks post partum has the ability to enhance the metabolism of glucose and insulin. Although significant but transient changes were observed in the number of circulating neutrophils and the intensity of CD18 expression on lymphocytes, interference in lymphocyte function related parameters such as lymphocyte blastogenesis and the percentages of lymphocytes expressing CD2, CD4, CD8, CD18 and CD49d were not observed. 


\section{ACKNOWLEDGEMENTS}

Boehringer Ingelheim, Germany, is acknowledged for a financial contribution.

\section{REFERENCES}

[1] Ackermann M., Peterhans E., Wyler R., DNA of bovine herpesvirus type 1 in the trigeminal ganglia of latently infected calves, Am. J. Vet. Res. 43 (1982) 36-40.

[2] Anderson B.H., Watson D.L., Colditz I.G., The effect of dexamethasone on some immunological parameters in cattle, Vet. Res. Commun. 23 (1999) 399-413.

[3] Andrews A.H., Laven R., Maisey I., Treatment and control of an outbreak of fat cow syndrome in a large dairy herd, Vet. Rec. 129 (1991) 216-219.

[4] Baldwin C.L., Teale A.J., Naessens F.G., Goddeeris B.M., MacHugh N.D., Morrison I., Characterisation of a subset of bovine T lymphocytes that express BoT4 by monoclonal antibodies and function: similarity to lymphocytes defined by human T4 and murine L3T4, J. Immunol. 136 (1986) 43854391.

[5] Bauer M.E., Perks P., Lightman S.T., Shanks N., Are adhesion molecules involved in stress-induced changes in lymphocyte distribution? Life Sci. 69 (2001) 1167-1179.

[6] Bernadina W.E., Duits A.J., Kalsbeek H.C., Wensing Th., Leibold W., Wentink G.H., Leukocyte adhesion deficiency in a Dutch Holstein calf: A case with a clear-cut family history, Vet. Immunol. Immunopathol. 37 (1993) 295-308.

[7] Burton J.L., Kehrli M.E. Jr., Regulation of neutrophil adhesion molecules and shedding of Staphylococcus aureus in milk of cortisoland dexamethasone-treated cows, Am. J. Vet. Res. 56 (1995) 997-1006.

[8] Burton J.L., Kehrli M.E. Jr., Effects of dexamethasone on bovine circulating $\mathrm{T}$ lymphocyte populations, J. Leukoc. Biol. 59 (1996) 90-99.

[9] Burton J.L., Kehrli M.E. Jr., Kapil S., Horst R.L., Regulation of L-selectin and CD18 on bovine neutrophils by glucocorticoids: effects of cortisol and dexamethasone, J. Leukoc. Biol. 57 (1995) 317-325.

[10] Butcher E.C., Picker L.J., Lymphocyte homing and homeostasis, Science 272 (1996) 60-66.
[11] Carlson G.P., Kaneko J.J., Influence of prednisolone on intravascular granulocyte kinetics of calves under nonsteady state conditions, Am. J. Vet. Res. 37 (1976) 149-151.

[12] Cronstein B.N., Kimmel S.C., Levin R.I., Martiniuk F., Weissmann G., A mechanism for the antiinflammatory effects of corticosteroids: The glucocorticoid receptor regulates leukocyte adhesion to endothelial cells and expression of endothelial-leukocyte adhesion molecule 1 and intercellular adhesion molecule 1, Proc. Natl. Acad. Sci. USA 89 (1992) 9991-9995.

[13] Cupps T.R., Fauci A.S., Corticosteroid-mediated immunoregulation in man, Immunol. Rev. 65 (1982) 133-155.

[14] Davies D.H., Carmichael L.E., Role of cellmediated immunity in the recovery of cattle from primary and recurrent infections with infectious bovine rhinotracheitis virus, Infect. Immun. 8 (1973) 510-518.

[15] Davis W.C., Ellis J.A., MacHugh N.D., Baldwin C.L., Bovine pan T-cell monoclonal antibodies reactive with a molecule similar to CD2, Immunology 63 (1988) 165-167.

[16] Doherty M.L., Bassett H.F., Quinn P.J., Davis W.C., Monaghan M.L., Effects of dexamethasone on cell-mediated immune responses in cattle sensitized to Mycobacterium bovis, Am. J. Vet. Res. 56 (1995) 13001306.

[17] Ellis J.A., Baldwin C.L., MacHugh N.D., Bensaid A., Teale A.J., Goddeeris B.M., Morrison W.I., Characterisation by monoclonal antibody and functional analysis of a subset of bovine T-lymphocytes that express BoT8, a molecule analogous to human CD8, Immunology 58 (1988) 351-358.

[18] Entman M.L., Youker K., Shapell S.B., Siegel C., Rothlein R., Dreyer W.J., Schmalstieg F.C., Wayne Smith C., Neutrophil adherence to isolated adult canine monocytes: evidence for a CD18-dependent mechanism, J. Clin. Investig. 85 (1990) 14971506

[19] Foster L.A., Clinical Ketosis, Vet. Clin North Am. Food Anim. Pract. 4 (1988) 253-267.

[20] Franklin S.T., Young J.W., Nonnecke B.J., Effects of ketones, acetate, butyrate, and glucose on bovine lymphocyte proliferation, J. Dairy Sci. 74 (1991) 2507-2514.

[21] Goulding N.J., Ogbourn S., Pipitone N., Biagini P., Gerli R., Pitzalis C., The inhibitory effect of dexamethasone on lymphocyte adhesion molecule expression and intercellular aggregation is not mediated by lipocortin 1, Clin. Exp. Immunol. 118 (1999) 376-383. 
[22] Hong S.L., Levine L., Inhibition of arachidonic acid release from cells as the biochemical action of anti-inflammatory corticosteroids, Proc. Natl. Acad. Sci. USA 73 (1976) 1730-1734.

[23] Jilma B., Voltmann J., Albinni S., Stohlawetz P., Schwarzinger I., Gleiter C.H., Rauch A., Eichler H.G., Wagner O.F., Dexamethasone down-regulates the expression of L-selectin on the surface of neutrophils and lymphocytes in humans, Clin. Pharmacol. Ther. 62 (1997) 562-568.

[24] Kaeberle M.L., Roth J.A., Effects of thiabendazole on dexamethasone-induced suppression of lymphocyte and neutrophil function in cattle, Immunopharmacology 8 (1984) 129-136.

[25] Mackay C.R., Marston W.L., Dudler L., Spertini O., Tedder T.F., Hein W.R., Tissuespecific migration pathways by phenotypically distinct subpopulations of memory $\mathrm{T}$ cells, Eur. J. Immunol. 22 (1992) 887-895.

[26] Ohmann H.B., Baker P.E., Babiuk L.A., Effect of dexamethasone on bovine leukocyte functions and bovine herpesvirus type-1 replication, Can. J. Vet. Res. 51 (1987) 350-357.

[27] Oldham G., Howard C.J., Suppression of bovine lymphocyte responses to mitogens following in vivo and in vitro treatment with dexamethasone, Vet. Immunol. Immunopathol. 30 (1992) 161-177.

[28] Philipp H., Goossens L., Limper J., Quirke J.F., Effect of dexamethasone isonicotinate on milk yield in ketotic cows, Vet. Rec. 128 (1991) 427.

[29] Pitzalis C., Pipitone N., Bajocchi G., Hall M., Goulding N., Lee A., Kingsley G., Lanchbury J., Panayi G., Corticosteroids inhibit lymphocyte binding to endothelium and intercellular adhesion: an additional mechanism for their anti-inflammatory and immunosupressive effect, J. Immunol. 158 (1997) 50075016.

[30] Pruett J.H., Fisher W.F., DeLoach J.R., Effect of dexamethasone on selected parameters of the bovine immune system, Vet. Res. Commun. 11 (1987) 305-323.

[31] Radostits O.M., Metabolic diseases: Ketosis in ruminants (Acetonemia in cattle, pregnancy toximia in sheep), in: Gay C.C., Blood D.C., Hinchcliff K.W. (Eds.), Veterinary Medicine, W.B. Saunders Co., London, 2000, pp. 1452-1462.

[32] Roth J.A., Kaeberle M.L., Hsu W.H., Effects of adrenocorticotropin administration on bovine polymorphonuclear leukocyte function and lymphocyte blastogenesis, Am. J. Vet. Res. 43 (1982) 412-416.

[33] Roth J.A., Kaeberle M.L., Effect of glucocorticoids on the bovine immune system, J. Am. Vet. Med. Assoc. 180 (1982) 894-901.

[34] Roth J.A., Kaeberle M.L., Hubbard R.D., Attempts to use thiabendazole to improve the immune response in dexamethasone-treated or stressed cattle, Immunopharmacology 8 (1984) 121-128.

[35] Rukkwamsuk T., Kruip T.A., Wensing T., Relationship between overfeeding and overconditioning in the dry period and the problems of high producing dairy cows during the postparturient period, Vet. Q. 21 (1999) 71-77.

[36] Schillinger D., Bucher W., Untersuchungen über den Einfluß von Glukokortikoiden und von ACTH auf das Blutbild des Rindes, Tierärztl. Umsch. 35 (1980) 651-656.

[37] Shpigel N.Y., Chen R., Avidar Y., Bogin E., Use of corticosteroids alone or combined with glucose to treat ketosis in dairy cows, J. Am. Vet. Med. Assoc. 208 (1996) 17021704.

[38] SPSS, SPSS Advance Statistics ${ }^{\mathrm{TM}}$, Version 10.0.5 (1999), SPSS Inc., Chicago, IL.

[39] Van de Water C., Haagsma N., Van Kooten P.J.S., Van Eden W., An enzyme-linked immunosorbent assay for the determination of chloramphenicol using a monoclonal antibody, Z. Lebensm. Unters. Forsch. 185 (1987) 202-207.

[40] Wentink G.H., Rutten V.P.M.G., van den Ingh T.S.G.A.M., Hoek A., Müller K.E., Wensing Th., Impared specific immunoreactivity in cows with hepatic lipidosis, Vet. Immunol. Immunopathol. 56 (1997) 77-83.

[41] Wierda A., Verhoeff J., Dorresteijn T., Wensing T., van Dijk S., Effects of two glucocorticoids on milk yield and biochemical measurements in healthy and ketotic cows, Vet. Rec. 120 (1987) 297-299.

[42] Winnicka A., Klucinski W., Kawiak J., Hoser G., Sikora J., Effect of Baypamun on blood leucocytes in normal and dexamethasone treated goats, J. Vet. Med. A Physiol. Pathol. Clin. Med. 47 (2000) 385-394.

[43] Yu D.T., Clements P.J., Pearson C.M., Effect of corticosteroids on exercise-induced lymphocytosis, Clin. Exp. Immunol. 28 (1977) 326-331. 